\title{
The Impact of Dynamic Two-Sided Platform Pricing on Fairness Perception in the Sharing Economy
}

\author{
Peter Angerer \\ University of Innsbruck \\ peter.angerer@uibk.ac.at \\ Gina Salomon \\ Management Center Innsbruck \\ sg9892@mci4me.at
}

\author{
Steffen Zimmermann \\ University of Innsbruck \\ steffen.zimmermann@uibk.ac.at \\ Daniel Provin \\ University of Innsbruck \\ daniel.provin@uibk.ac.at
}

Kurt Matzler

University of Innsbruck

kurt.matzler@uibk.ac.at

\author{
Gerald Pale \\ University of Innsbruck \\ gerald.pale@student.uibk.ac.at \\ Wolfgang Kathan \\ University of Innsbruck \\ wolfgang.kathan@uibk.ac.at
}

\begin{abstract}
From an economic perspective, dynamic pricing seems to be the profit maximizing pricing strategy for consumer-to-consumer (C2C) sharing platforms because it allows balancing supply and demand over time. Based on distributive justice and equity theory we investigate how two characteristics of dynamic pricing, namely 'fee changes over time' and 'fee differences across consumer groups', influence fairness perception and intention to share of consumers. Using a laboratory experiment, we find that fee differences between lenders and borrowers is the dominant source of negative fairness perception, which in turn results in a lower intention to share, especially for the consumer group that is charged with a higher fee. Consequently, C2C sharing platforms have to be aware of this negative effect from fairness perception when they implement a dynamic two-sided platform pricing strategy to maximize profits.
\end{abstract}

\section{Introduction}

The consumer-to-consumer (C2C) sharing ecosystem is characterized by three classes of participants (cf., [8]). Lenders are consumers that own products and grant other consumers temporary access to these products by charging a sharing price. Borrowers are consumers that do not own products, but aim to get temporary access to products by paying the sharing price to lenders. $\mathrm{C} 2 \mathrm{C}$ sharing platforms are accessibility-based systems that provide a matchmaking service (e.g., listings of products, consumer ratings, payment services, etc.) facilitating sharing transactions between lenders and borrowers [3]. The majority of C2C sharing platforms such as Airbnb.com, 9Flats.com, Wimdu.com and Zilok.com charge platform fees to lenders and/or borrowers for using their matchmaking service (cf., [16]) to maximize profits. These fees are usually set constant over time but subsidize either lenders or borrowers over the respective other group (e.g., Airbnb.com charge a fee to lenders of 3\% and a fee to borrower $5-15 \%$ of the total sharing price of an apartment) [9].

From traditional one-sided markets, sophisticated pricing strategies are known where prices are adapted in response to periodic demand fluctuations and inventory levels [10] or changing environmental conditions [21]. For example, airlines distinguish consumers according to their price sensitivity [29] or soft drink vendors tried to adjust prices according to the surrounding temperature [21]. Such pricing strategies are summarized by the term dynamic pricing and can be seen as a variation of traditional price discrimination [17]. Dynamic pricing is generally defined as "a pricing strategy in which prices change over time, across consumers, or across product/service bundles" [20, p. $63]$. For the majority of $\mathrm{C} 2 \mathrm{C}$ sharing platforms, the latter is of minor interest because there is typically no differentiation in the provided matchmaking service. Subsequently, we focus on fee changes over time and fee differences across consumer groups (in our context across lenders and borrowers) in the context of dynamic two-sided platform pricing in $\mathrm{C} 2 \mathrm{C}$ sharing platforms. Please note that we are analyzing dynamic two-sided platform pricing (i.e., dynamically changing platform fees over time that may differ between lenders and borrowers) which could be applied for the majority of C2C sharing platforms such as Airbnb.com, 9Flats.com, Wimdu.com and Zilok.com that do not set the sharing 
price (i.e. the sharing price is set by the lender). Consequently, we do not analyze dynamically changing sharing prices, which is a pricing strategy applied by Uber.com (called surge pricing). Uber.com is substantially different to the $\mathrm{C} 2 \mathrm{C}$ sharing platforms mentioned above as Uber.com also sets the sharing price and dynamically adjusts it to eliminate imbalance of supply and demand [32].

Angerer et al. [3] show that from an economic perspective $\mathrm{C} 2 \mathrm{C}$ sharing platforms are profit maximizing only if supply for a product on a $\mathrm{C} 2 \mathrm{C}$ sharing platform equals demand (cleared market). This market clearing condition can be maintained by dynamically adjusting platform fees over time and across lenders and borrowers.

Although, such a dynamic pricing strategy might be profit maximizing from a pure economic perspective, it might at the same time cause negative effects on intention to share due to a negative fairness perception of consumers [27] which is indicated by theories such as distributive justice [18] and equity theory [2].

In extant literature, the effect of dynamic pricing on fairness perception and purchase intention have been studied for traditional industries with one-sided pricing models. Thereby, differences in fairness perception predominantly results from price changes over time by consumers that compare own prices with prices that have been paid by former consumers for the same product $[14,22]$. These studies conclude that dynamic pricing significantly affects fairness perception [22] in a negative way because it causes uncertainties [17] or violates established pricing norms [13]. The negative effect on fairness perception is getting lager the higher the price changes over time are [14]. It is also well established that consumers "are willing to resist unfair firms even at a positive cost" [19, p. 285]. Thus, purchase intention of consumers is significantly affected by fairness perception [23]. In more detail, purchase intention is positively related to fairness perception [5, 13, 19, 33, 34]. However, in two-sided platform businesses such as the sharing economy, consumers can not only compare their platform fees with platform fees of former consumers. They can also compare their platform fees with platform fees of their transaction partner. How fee changes over time and fee differences between lenders and borrowers affect fairness perception and consequently intention to share have not been studied so far. Accordingly, we state the following research question:

How does dynamic pricing of a C2C sharing platform influence the fairness perception and intention to share of consumers?

To answer this research question we conducted a laboratory experiment using a 3x4 within-subject full factorial design. We use the independent variables fee differences across consumer groups with three manipulations and fee changes over time with four manipulations to test the effect of dynamic pricing on the mediating variable fairness perception and the effect of fairness perception on the dependent variable intention to share. During the experiment the independent variable fee differences across consumer groups is manipulated in a way that the fee of the participant is the same, higher or lower than the fee of the transaction partner with whom the participant is sharing a product. The independent variable fee changes over time is manipulated in a way that no fee changed in the past, only the fee of the participant changed in the past, only the fee of the transaction partner changed in the past, or both fees changed in the past.

We find that fee changes over time as well as fee differences across consumer groups have a negative effect on fairness perception and intention to share. Comparing the effect sizes, fee differences across consumer groups have a substantially higher negative effect on fairness perception than fee changes over time. Especially the consumer group that is charged with a higher fee has a lower intention to share resulting from negative fairness perception. Consequently, C2C sharing platforms have to be aware, especially of the negative effects resulting from fee differences between lenders and borrowers on fairness perception when they implement a dynamic two-sided pricing strategy. Overall, C2C sharing platforms have to balance the positive economic effect described in [3] and the negative effect of fairness perception on intention to share.

\section{Theoretical background and research model}

Our research is informed by the theory of distributive justice and equity theory. "Both equity theory and distributive justice suggest that perception of fairness are induced when a person compares an outcome [...] with a comparative other's outcome" [34, p. 1]. Distributive justice explains "the allocation of rewards on the basis of individual contributions to an exchange relationship" [7, p. 265] and states that "a man's rewards in exchange with others should be proportional to his investments" [18, p. 235]. Equity theory states that equity exists for a person "whenever he perceives that the ratio of his outcomes to inputs and the ratio of other's outcomes to other's inputs" are equal [2, p. 280].

In both theories, a situation is considered as fair when the compared parties get the same rewards to their investments [31] and as unfair when a discrepancy 
appears in the comparison [7]. According to [34] distributive justice focuses on the comparison of parties that are involved in the same transaction and equity theory broadens this focus to a comparison of parties that are not necessarily in the same transaction.

In our research model depicted in Figure 1, we follow the distinction of [34] and use distributive justice and equity theory to hypothesize the effects of the independent variables fee changes over time and fee differences across consumer groups on the mediating variable fairness perception that in turn affects our dependent variable intention to share.

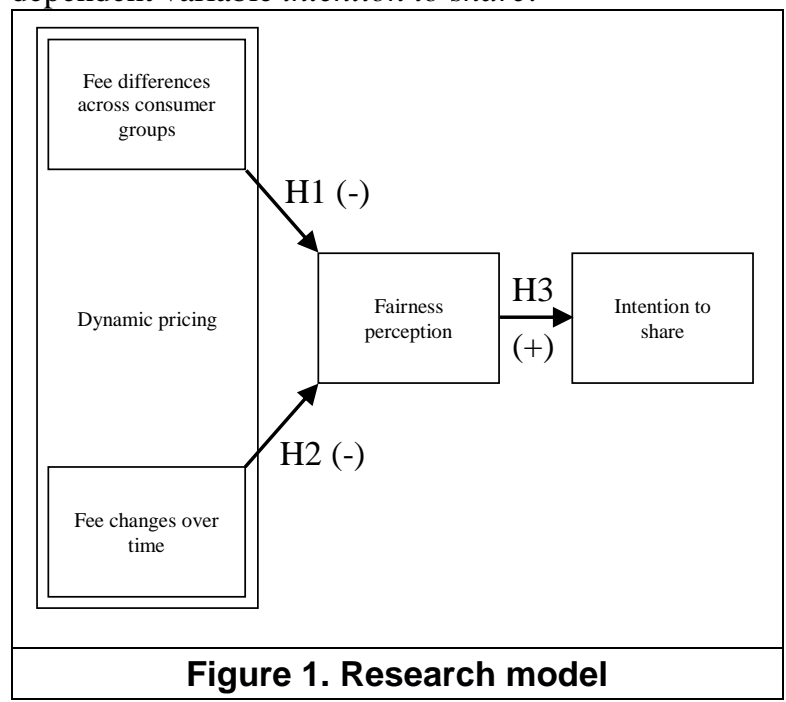

Contemporary $\mathrm{C} 2 \mathrm{C}$ sharing platforms charge fees to lenders and/or borrowers where typically either the lender or borrower is advantaged over the other in terms of the level of fee they have to pay for the matchmaking service the $\mathrm{C} 2 \mathrm{C}$ sharing platform provides. In other words, one consumer group (i.e., lenders or borrowers) have to pay a lower fee for the matchmaking service of the $\mathrm{C} 2 \mathrm{C}$ sharing platform than the other. Treating the matchmaking service of the $\mathrm{C} 2 \mathrm{C}$ sharing platform as a reward that is equal for lenders and borrowers and considering the respective lender and borrower fee as their individual investment to use the matchmaking service, fee differences across consumer groups will result in a deviation from an equal ratio of reward to investment for lenders and borrowers. As we focus on $\mathrm{C} 2 \mathrm{C}$ sharing platforms where the sharing price is set by the lender and not by the platform (e.g., Airbnb.com), we do neither consider further investments of borrowers (e.g., room charge, cleaning fee) and lenders (e.g., maintenance costs) nor additional rewards of borrowers (e.g., quality of the room) and lenders (e.g., room charge, cleaning fee) that are captured in the sharing price. Thus, our focus is whether lenders and borrowers perceive the platform fees as investment for using the matchmaking service provided by a C2C sharing platform as fair.
In addition, consumers do also act in a self-interested way and thus perceive being disadvantaged less fair than being advantaged [34]. However, there is some evidence that "being advantaged is not always considered the fairest" [33, p. 893]. As lenders and borrowers are involved in the same transaction [34], we use distributive justice to hypothesize that fee differences between lenders and borrowers reduce fairness perception [7, 18, 31]. We expect that fee differences across consumer groups of a joint sharing transaction have a negative effect on fairness perception. Therefore, we hypothesize that:

H1: Fee differences across consumer groups have a negative effect on fairness perception.

Angerer et al. [3] propose that $\mathrm{C} 2 \mathrm{C}$ sharing platforms should dynamically adjust its lender and borrower fee over time in order to preserve the clear market condition and subsequently be profit maximizing. In accordance to equity theory also past sharing transactions of both lenders and borrowers are within the scope of comparison. For example, a lender who has repeatedly shared an apartment via Airbnb.com may recognize that she has paid different platform fees over time for using the matchmaking service. Treating the matchmaking service of the $\mathrm{C} 2 \mathrm{C}$ sharing platform as reward and the platform fees as investments, fee changes over time will result in a deviation from equal ratios of reward to investment when comparing past with current platform fees. In addition, fee changes over time may also cause uncertainties when estimating the outcome of a possible sharing transaction and in turn have a negative influence on fairness perception [17]. Accordingly, we hypothesize that:

H2: Fee changes over time have a negative effect on fairness perception.

Consumers punish companies if they perceive their behavior as unfair [19] by spreading negative word of mouth, filing a complaint or searching for alternatives $[13,34]$. Most literature evaluates the effect of perceived fairness with regard to purchase intention and conclude that fairness perception is positively related to purchase intention $[5,13,19,33,34]$. Thereby, purchase intention is seen "as a surrogate measure of actual purchase" [22, p. 544]. Although the effect of fairness perception on purchase intention was examined in the context of e-commerce and retailing (cf., [5, 13, 19, 33, 34]), we expect the findings to be also applicable to the sharing economy. Thus, we substitute purchase intention by intention to share and expect a similar effect as for purchase intention. Therefore, we hypothesize that:

H3: Fairness perception has a positive effect on intention to share. 


\section{Research method and study design}

To test our hypothesis we conducted a laboratory experiment using a $3 \times 4$ within-subject full factorial design. The two independent variables are fee differences across consumer groups (three different manipulations) and fee changes over time (four different manipulations). Fairness perception is the mediating variable that mediates the effect of the independent variables on the dependent variable intention to share.

\subsection{Case description}

A sharing transaction provided by the $\mathrm{C} 2 \mathrm{C}$ sharing platform Airbnb.com is used as a case example throughout the experiment. Airbnb.com is an accommodation-sharing platform that connects lenders who have an accommodation to share and borrowers who are willing to borrow an accommodation. Thereby, Airbnb.com is not the owner of the accommodation but rather provide the matchmaking service that allows lenders and borrowers to share an accommodation. We decided to use Airbnb.com as a case example, because the business model is commonly known and, unlike Uber.com, Airbnb.com follows the common pricing strategy of $\mathrm{C} 2 \mathrm{C}$ sharing platforms (setting a lender and/or borrower fee for using the matchmaking service but not setting the sharing price). Therefore, we expect that our findings are applicable for the majority of $\mathrm{C} 2 \mathrm{C}$ sharing platforms that follow the same pricing strategy. In our experiment, we created a scenario that consists of a mockup of a fictitious, available Airbnb apartment in Paris including a photo and a description. The participants that are randomly assigned to be a lender want to share this apartment for two days and the participants that are randomly assigned to be a borrower want to spend two holidays in Paris and borrow the apartment. If a sharing transaction is concluded (i.e., a borrower decides to borrow an accommodation from a lender), Airbnb.com charges platform fees to the lender and the borrower [1]. In our experiment, we deliberately manipulate these fees to investigate the effects on fairness perception and intention to share.

\subsection{Independent variables}

Dynamic two-sided pricing of a $\mathrm{C} 2 \mathrm{C}$ sharing platform is represented by the two independent variables, fee differences across consumer groups and fee changes over time.

Fee differences across consumer groups $(f)$ is manipulated in three different ways: (A) equality, (B) disadvantaged inequality, and (C) advantaged inequality. In other words, the fee of the participant can be (A) the same, (B) higher, or (C) lower than the fee of the transaction partner. In the inequality treatments (B, and $\mathrm{C}$ ), the fees are manipulated in a way that the fee differences between the transaction partners represent $20 \%$ (as recommended by Blattberg et al. [4]).

Fee changes over time $(\sigma)$ is manipulated in four different ways: (1) equally stable, (2) disadvantageddynamic, (3) advantaged-dynamic, and (4) equally dynamic. In other words, in (1) the fee of the participant and the fee of the transaction partner did not change in the past, (2) only the participant's fee changed in the past, (3) only the transaction partner's fee changed in the past, (4) both fees changed in the past. Combining the manipulations of the two independent variables in a full factorial design results in 12 treatments illustrated in Table 1.

\section{Table 1. Experimental design}

\begin{tabular}{|c|c|c|c|c|}
\hline $\begin{array}{l}\text { fee } \\
\text { acference } \\
\text { consumer groups }\end{array}$ & $\begin{array}{c}(1) \\
\text { Equally } \\
\text { stable } \\
\sigma_{\text {own }}=0 \\
\sigma_{\text {tp }}=0\end{array}$ & $\begin{array}{c}(2) \\
\text { Disadvantaged } \\
\text { dynamic } \\
\sigma_{\text {own }}>0 \\
\sigma_{\mathrm{tp}}=0\end{array}$ & $\begin{array}{c}(3) \\
\text { Advantaged } \\
\text { dynamic } \\
\sigma_{\text {own }}=0 \\
\sigma_{\text {tp }}>0\end{array}$ & $\begin{array}{c}(4) \\
\text { Equally } \\
\text { dynamic } \\
\sigma_{\text {own }}>0 \\
\sigma_{\text {tp }}>0\end{array}$ \\
\hline $\begin{array}{c}\text { (A) Equality } \\
f_{\text {own }}=f_{t p}\end{array}$ & A1 & A2 & A3 & A4 \\
\hline $\begin{array}{l}\text { (B) Disadvantaged inequality } \\
f_{\text {own }}>f_{\mathrm{tp}}\end{array}$ & B1 & B2 & B3 & B4 \\
\hline $\begin{array}{c}\text { (C) Advantaged inequality } \\
f_{\text {own }}<\mathrm{f}_{\mathrm{tp}}\end{array}$ & $\mathrm{C} 1$ & $\mathrm{C} 2$ & C3 & $\mathrm{C} 4$ \\
\hline \multicolumn{5}{|c|}{$\begin{aligned} \text { own } & \text { variables that are dedicated to the participant } \\
\text { tp } & \text { variables that are dedicated to the transaction partner of the participant } \\
\text { f } & \text { fee differences across consumer groups } \\
\sigma & \text { fee changes over time }\end{aligned}$} \\
\hline
\end{tabular}




\subsection{Mediating variable}

Besides economic effects of dynamic pricing on intention to share [3], fairness perception is considered to have a mediating effect between dynamic pricing and intention to share as well. Thus, fairness perception is considered as a mediating variable $[22,34]$. In each treatment, the participants answer the question "How fair do you consider the fee you have to pay?". Following Campbell [5], we use a single-item scale to measure the fairness perception a participant experience in each treatment. The answer "The fee I have to pay is fair" is measured on a seven-point Likert-scale with numbers from one to seven with end labelling of "totally disagree" and "totally agree". Following the findings of Moors et al. [24], we choose an agreement scale (only positive numbers 1 to 7 ) instead of bipolar scale (positive and negative numbers -3 to +3 ) to avoid overly extreme responses. A high value ("totally agree") indicates that a participant perceives the fee as fair while a low value ("totally disagree") indicates that the fee is considered as unfair.

\subsection{Dependent variable}

We measure intention to share as likelihood that the participants are willing to share or borrow. Therefore, we ask the question "How likely would you [share/borrow] this apartment" and following Campbell [5], participants can answer on a single-item scale. In our experiment, the dependent variable intention to share is immediately measured after the mediating variable fairness perception. This can cause a risk of covariation when using the same scales for both items [26]. To counter this risk we use a different scale to measure intention to share. Thus, participants are asked to answer "My likelihood to [share/borrow] the apartment" on a slider-scale from $0-100 \%$ where participants can choose their answer in ten percentage steps. A higher percentage rate on the scale indicates a higher intention to share.

\subsection{Control variables}

The $\mathrm{C} 2 \mathrm{C}$ sharing economy consists of two consumer groups (lenders and borrowers). In our experiment, we randomly assigned participants to the two consumer groups. In order to avoid unintended effects from the assigned role, we control for these effects. We name the control variable role of participant and effect-coded it with -1 for lender and +1 for borrower.

We use Airbnb.com as a case example for our experiment. However, using a specific example in a laboratory experiments may cause unintended influence. For example, the participants can connect to the case example in the experiment with positive or negative memories of prior experiences [12]. To control for the influence of prior experience we ask all participants whether they had ever shared or borrowed an accommodation via Airbnb.com. Subsequently, we name the control variable prior experience and effectcoded it with -1 for no prior experience and 1 for prior experience with Airbnb.com. We decide to use effectcoding, because especially for the role of participant we do not want to define either lender or borrower as reference group which would be needed when using dummy-coding (e.g., 0 for lender and 1 for borrower). In addition, mean differences on the dependent variable caused by an effect-coded variable can be interpreted with respect to the grand mean of all groups rather than the control group [15].

\subsection{Tasks and procedures}

Undergraduates of two Austrian universities participated in our experiment. 263 participants took part in the experiment, which was conducted in April and May 2016. The participants were asked to conduct the experiment voluntarily in a lecture of their regular courses. As incentive two $25 €$ coupons of the online market place Amazon.com were raffled among all participants. In the course of the approximately 25 minute long experiment the participants are asked to express their fairness perception along with their intention to share for each of the 12 treatments.

At the beginning, all participants are randomly assigned to conduct the experiment either as a lender or as borrower (role of participant). The following introduction to the experiment is respecting the role each participant is assigned to and consists of general information about Airbnb.com, a clarification on the roles they are assigned to and general information about the fees charged by Airbnb.com. Then all participant are introduced to the provided scenario apartment in Paris. In a baseline treatment, the participants are asked about their intention to share the apartment and the maximum platform fee they would consider as fair. The given fee is used as a basis to calculate the fees in the 12 treatments to mitigate anchoring effects as a result of an insufficient adjusted starting point [25] of the fee. In the following 12 treatments, the participants are faced by different manipulations of the independent variables. Table 2 shows four exemplified treatments with the visualization of the independent variables. Fee difference across consumer groups are visualized with vertical bars. The same height indicate that both fees are the same (e.g., treatment (A1)) and different heights indicate that the fee is different across consumer groups (e.g., treatment (B1)). Fee changes over time are 
Table 2. Treatment visualization

\begin{tabular}{|c|c|c|c|c|c|}
\hline & Visualization s & $n$ & the experiment & & \\
\hline & Fee of participant & & $\begin{array}{c}\text { Fee of transaction } \\
\text { partner }\end{array}$ & & \\
\hline A1 & TIME & تي & TIME & $\begin{array}{l}\text { (A) } \\
\text { Equality } \\
f_{\text {own }}=f_{t p}\end{array}$ & $\begin{array}{c}(1) \\
\text { Equally stable } \\
\sigma_{\text {own }}=0 \\
\sigma_{\text {tp }}=0\end{array}$ \\
\hline B1 & TIME & 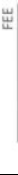 & TIME & $\begin{array}{c}(\mathrm{B}) \\
\text { Disadvantaged inequality } \\
\mathrm{f}_{\text {own }}>\mathrm{f}_{\mathrm{tp}}\end{array}$ & $\begin{array}{c}(1) \\
\text { Equally stable } \\
\sigma_{\text {own }}=0 \\
\sigma_{\text {tp }}=0\end{array}$ \\
\hline $\mathrm{C} 3$ & TIME & 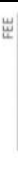 & TIME & $\begin{array}{c}(\mathrm{C}) \\
\text { Advantaged Inequality } \\
\mathrm{f}_{\mathrm{own}}<\mathrm{f}_{\mathrm{tp}}\end{array}$ & $\begin{array}{c}(3) \\
\text { Advantaged dynamic } \\
\sigma_{\text {own }}=0 \\
\sigma_{\text {tp }}>0\end{array}$ \\
\hline $\mathrm{C} 4$ & 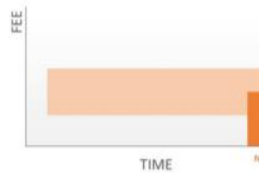 & జّ & TIME & $\begin{array}{c}(\mathrm{C}) \\
\text { Advantaged Inequality } \\
\mathrm{f}_{\mathrm{own}}<\mathrm{f}_{\mathrm{tp}}\end{array}$ & $\begin{array}{c}(4) \\
\text { Equally dynamic } \\
\sigma_{\text {own }}>0 \\
\sigma_{\text {tp }}>0\end{array}$ \\
\hline
\end{tabular}

visualized as a horizontal corridor in which past fees have changed (e.g., treatment (C4)). This corridor is chosen in a way that past fees could have been lower or higher than the actual fee. Fees that have not changed over time are represented by a horizontal line (e.g., treatment (B1)). In each treatment all participants give their answers on fairness perception and intention to share. To eliminate carry-over effects, which may occur when participants answer multiple treatments in a row [6], the sequence of the treatments is randomized for each participant. In the end, we ask all participants if they ever used Airbnb.com before the experiment to measure our control variable prior experience. Additionally, the participants are asked to provide demographic information like gender, age, education, and income.

The experiment was realized in the web-based software Soscisurvey.de. Before we conducted the experiment, we did several pre-tests to check whether the participants observe the manipulations and to eliminate problems and ambiguity [28].

\section{Analysis and results}

As a first step, we perform data cleaning. In the course of this process we delete data from participants who have not finished the experiment, who have missing values inside their dataset, or did not correctly observe the manipulations. After data cleaning we end up with a data set of $\mathrm{N}=220$ participants where 108 participants were acting as borrowers and 112 participants were acting as lenders. Table 3 gives an overview of the demographics of our participants.

To test the effect of fee changes across consumer groups and fee changes over time on fairness perception

Table 3. Demographic data of participants

\begin{tabular}{|c|c|c|c|c|c|c|c|c|}
\hline & \multicolumn{2}{|c|}{ Gender } & \multicolumn{2}{|c|}{ Age } & \multicolumn{2}{|c|}{ Education } & \multicolumn{2}{|c|}{ Income } \\
\hline \multirow{6}{*}{$\begin{array}{l}\text { Borrower } \\
n=108\end{array}$} & Female & $45.4 \%$ & Mean (S.D.) & $23.17(2.219)$ & Apprenticeship & $6.3 \%$ & No income & $33.3 \%$ \\
\hline & Male & $54.6 \%$ & Median & 23 & A-Levels & $58.9 \%$ & $<500 €$ & $28.7 \%$ \\
\hline & Inter Sex & $0 \%$ & Range & $20-32$ & Bachelor & $27.7 \%$ & $501-1500 €$ & $34.3 \%$ \\
\hline & & & & & Master & $3.6 \%$ & $1501-2500 €$ & $0.9 \%$ \\
\hline & & & & & other & $2.7 \%$ & $2501-3500 €$ & $1.9 \%$ \\
\hline & & & & & No answer & $8.0 \%$ & No answer & $0.9 \%$ \\
\hline \multirow{6}{*}{$\begin{array}{l}\text { Lender } \\
\mathrm{n}=112\end{array}$} & Female & $46.4 \%$ & Mean (S.D.) & $23.05(2.172)$ & Apprenticeship & $2.8 \%$ & No income & $33.0 \%$ \\
\hline & Male & $52.7 \%$ & Median & 22 & A-Levels & $57.4 \%$ & $<500 €$ & $31.3 \%$ \\
\hline & Inter Sex & $0.9 \%$ & Range & $20-30$ & Bachelor & $34.3 \%$ & $501-1500 €$ & $32.1 \%$ \\
\hline & & & & & Master & $1.9 \%$ & $1501-2500 €$ & $2.7 \%$ \\
\hline & & & & & other & $1.0 \%$ & $2501-3500 €$ & $0.9 \%$ \\
\hline & & & & & No answer & $2.6 \%$ & No answer & $0 \%$ \\
\hline
\end{tabular}


we use two-way repeated measure analysis of variance (ANOVA) with role of participant and prior experience as covariates. We further use Pearson's correlation and regression analysis to test the effect of fairness perception on intention to share. For computation and visualization we use IBM SPSS Statistics version 24.

\subsection{Testing assumptions}

Shapiro-Wilk test reports non-normally distributed data $\mathrm{p}<.001$. However, current research shows strong support for the robustness of analysis of variance under application of non-normally distributed data. A deviation of up to \pm 2 for skewness and \pm 6 for kurtosis from normally distributed data did not influence the results significantly [30]. The data in our dataset is within these boundaries.

We use Mauchly's test of sphericity to test whether the variances of the differences between different treatments are equal. The result shows that we need to correct certain degrees of freedom in the following analysis using the Greenhouse-Geisser estimate of sphericity [11].

\subsection{Results}

The results indicate a significant main effect of fee differences across consumer groups on fairness perception $\mathrm{F}(1.742,218)=165.016 ; \mathrm{p}<.001 ; \eta^{2}=.277$. In detail, consumers perceive equality as fairest $(\mathrm{M}=$ 5.390). Within-subject contrasts reveal that consumers do act in a self-interested way and perceive advantaged inequality $(\mathrm{M}=5.075)$ significantly fairer than disadvantaged inequality $(\mathrm{M}=3.607), \mathrm{F}(1,218)=$ $141.751 ; \mathrm{p}<.001$. The mean fairness perception drops by $1.468 ; \mathrm{p}<.001$. However, despite acting selfinterested consumers perceive advantaged inequality significantly less fair than equality $\mathrm{F}(1,218)=15.197$; $\mathrm{p}<.001$. The mean fairness perception drops by .315; $\mathrm{p}$ $=.001$. Subsequently H1 is supported.

The results further indicate a significant main effect of fee changes over time on fairness perception $\mathrm{F}(3$, $218)=5.264 ; \mathrm{p}=.001 ; \eta^{2}=.0028$. However, withinsubject contrasts reveal that there are non-significant effects between advantaged dynamic vs. equally dynamic $\mathrm{F}(1,218)=.361 ; \mathrm{p}=.554$ and between equally stable vs. equally dynamic $\mathrm{F}(1,218)=1.405 ; \mathrm{p}=.237$. The effect between disadvantaged dynamic vs. equally dynamic remain significant $\mathrm{F}(1,218)=7.719 ; \mathrm{p}=.006$. Thus, consumer favor stable fees over dynamic fees. In more detail, consumers fairness perception is highest with equally stable fees $(M=4.815)$. However, the difference in mean values of equally dynamic fees $(\mathrm{M}=$ 4.708), advantaged dynamic fees $(\mathrm{M}=4.682)$, and disadvantaged dynamic fees $(M=4.558)$ is rather small. Subsequently, $\mathrm{H} 2$ is supported.

When considering the interaction effect of the independent variables fee differences across consumer groups and fee changes over time, our results show a significant impact on fairness perception $\mathrm{F}(5.655,218)$ $=4.080 ; \mathrm{p}=.001 ; \eta^{2}=.0043$. This indicates that fairness perception across different levels of fee changes over time is different for equality (A), disadvantaged inequality (B) and advantaged (C) inequality of fees. This can be seen in Figure 2 by the converging and crossing lines. Figure 2 also illustrates that fairness perception of disadvantaged dynamic, advantaged dynamic and equally dynamic fee changes over time behaves approximately the same across different levels of fee differences across consumer groups. Thus, relative difference between fairness

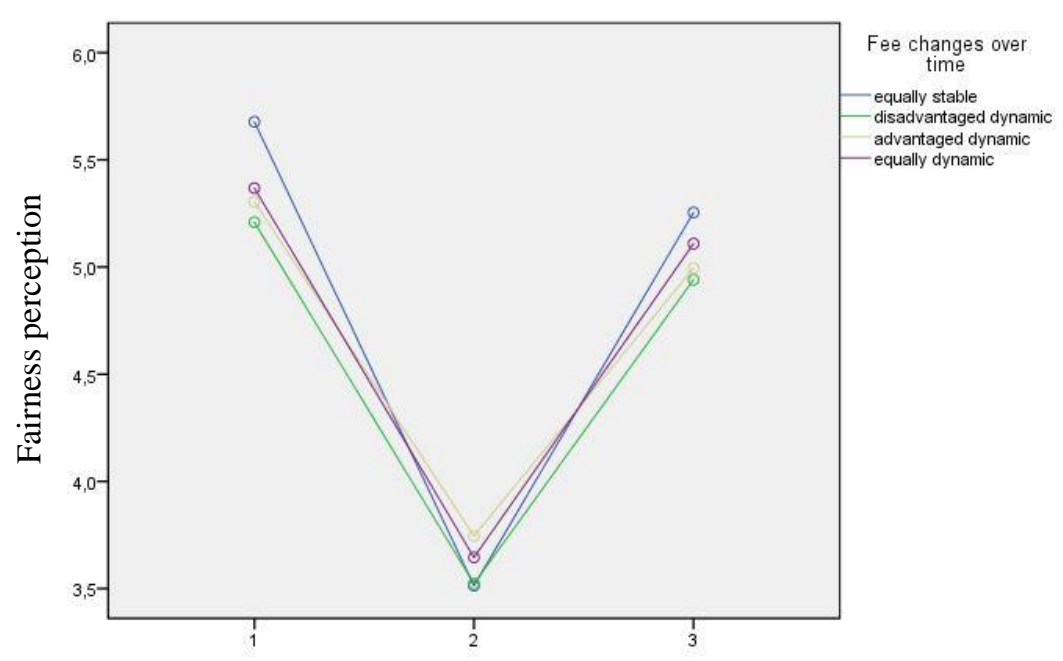

Fee differences across consumer groups

Figure 2. Interaction effect of fee differences across consumer groups ${ }^{*}$ fee changes over time 
perception of different levels of fee changes over time are approximately the same. Apart from that, consumers who are not faced with fee changes over time (equally stable) seem to be most negatively influence by disadvantaged inequality (B) of fees (crossing lines). However, within-subject contrasts show only one significant interaction effect when fee differences across consumer groups change between disadvantaged inequality (B) and advantaged inequality (C) and fee changes over time change between equally stable and equally dynamic fee changes over time $\mathrm{F}(1,218)=$ 5.320; $\mathrm{p}=.022$. Thus, when switching from disadvantaged (B) to advantaged inequality (C), participants who are facing equally stable fees over time gain a higher increase in fairness perception compared to participants faced with equally dynamic fee changes over time. The remaining contrasts are not significant ( $\mathrm{p}$ $>$.05).

The control variable role of participant has a significant effect on fairness perception $\mathrm{F}(1,218)=$ $6.487 ; \mathrm{p}=.012 ; \eta^{2}=.029$. However, only $2.9 \%$ percent of total variance is caused by the control variable role of participant. In detail, mean fairness perception of lenders $(\mathrm{N}=112 ; \mathrm{M}=4.537 ; \mathrm{SD}=.881)$ is .312 lower than mean fairness perception of borrowers $(\mathrm{N}=108$; $\mathrm{M}=4.849 ; \mathrm{SD}=.988$ ).

With respect to the control variable prior experience we could not find a significant effect on fairness perception $\mathrm{F}(1,218)=2.932 ; \mathrm{p}=.088 ; \eta^{2}=.013$. In detail, mean fairness perception of participants who had already shared or borrowed an accommodation $(\mathrm{N}=71$; $\mathrm{M}=4.838 ; \mathrm{SD}=.893$ ) is not significantly different from those participants who had no prior experience with Airbnb.com $(\mathrm{N}=149 ; \mathrm{M}=4.620 ; \mathrm{SD}=.966)$.

Using pearson's correlation we find that fairness perception is correlated with intention to share with $\mathrm{r}(2640)=.560, \mathrm{p}<.001$. To examine the relation between fairness perception and intention to share we perform a linear regression. Thereby, we use the method of least squares to calculate the resulting regression line. The results show that fairness perception significantly predicts intention to share with an interceptor $\beta_{0}=$
$21.362, \mathrm{t}(2638)=16.779, \mathrm{p}<.001$ and a gradient $\beta_{1}=$ $8.841, \mathrm{t}(2637)=34.690, \mathrm{p}<.001$. Fairness perception also predicts a significant proportion of variance in intention to share $\mathrm{R}^{2}=.313 ; \mathrm{F}(1,2638)=1203.38 ; \mathrm{p}<$ .001 . Subsequently, an increase in fairness perception by one point increases intention to share by $8.841 \%$. Thus, fairness perception is positively related to intention to share. Furthermore, fairness perception is able to predict a significant $31.3 \%$ of variation in intention to share. Consequently, H3 is supported.

\section{Discussion}

Angerer et al. [3] proof in an analytical economic model that $\mathrm{C} 2 \mathrm{C}$ sharing platforms maximize profits if they utilize a dynamic two-sided pricing strategy to balance demand and supply. Given that supply and demand for sharing a product or service are likely to vary over time, this results in fee differences across consumer groups and fee changes over time. When comparing the effect of fee differences across consumer groups and fee changes over time on fairness perception, we find that the effect size of fee differences across consumer groups $\left(\eta^{2}=.277\right)$ is much stronger compared to the effect size of fee changes over time $\left(\eta^{2}=.0028\right)$. This implies that consumers in the sharing economy judge fairness predominantly by comparing their own platform fees with the platform fees of the transaction partner and, contrary to the findings in extant literature on fairness perception for one-sided pricing models [14, 22], different fees of prior consumers only have a subordinate effect on consumers' fairness perception in the sharing economy.

Our results also show a significant positive relation between fairness perception and intention to share which is in line with findings of extant literature where a positive relation between fairness perception and purchase intention is supported [5, 13, 19, 33, 34]. More interesting, we found that a significant part $(31.3 \%)$ of variance in consumers' intention to share (consumer behavior) is attributable to fairness perception. This

Table 4. Results summary

\begin{tabular}{|c|c|c|c|c|c|c|c|}
\hline \multicolumn{8}{|c|}{ Independent Variables } \\
\hline Source & SS & $\mathrm{df}$ & MS & $\mathrm{F}$ & p-value & Partial $\eta^{2}$ & $\eta^{2}$ \\
\hline $\mathrm{f}$ & 1476.955 & $1.742+$ & 847.818 & 165.016 & $\leq .001 *$ & .432 & .277 \\
\hline$\sigma$ & 14.809 & 3 & 4.936 & 5.264 & $\leq .001 *$ & 0.024 & .0280 \\
\hline $\mathrm{f}^{*} \sigma$ & 22.73 & $5.655+$ & 4.027 & 4.080 & $\leq .001 *$ & .018 & .0043 \\
\hline \multicolumn{8}{|c|}{ Control Variables } \\
\hline $\mathrm{r}$ & 5.626 & 1 & 5.626 & 6.487 & $.012 *$ & .0012 & .029 \\
\hline $\mathrm{a}$ & 2.543 & 1 & 2.543 & 2.932 & .088 & .0006 & .013 \\
\hline \multicolumn{4}{|c|}{$\begin{array}{l}\text { f fee differences across consumer groups } \\
\sigma \text { fee changes over time } \\
r \text { role of participant } \\
\text { a prior experience with Airbnb }\end{array}$} & \multicolumn{4}{|c|}{$\begin{array}{ll}* & \text { Significant with } \mathrm{p}<\alpha=0.05 \\
+ & \text { Greenhouse-Geisser correction } \\
\text { SS } & \text { Sum of Squares } \\
\text { df } & \text { degree of freedom } \\
\text { MS } & \text { mean Squares } \\
\end{array}$} \\
\hline
\end{tabular}


implies that consumers in the sharing economy do not strictly adopt the behavior of pure economic agents (homo economicus) with complete rationality but are also influenced by behavioral factors such as perceived fairness (cf., [19]).

Our analysis of the control variable role of participant reveals that the mean fairness perception of lenders is slightly lower than mean fairness perception of borrowers. According to equity theory, one reason for this might be that lenders perceive the reward of the matchmaking service slightly lower than borrowers. However, this difference is not substantial which supports our implicit assumption that the reward from using the matchmaking service is similar for lenders and borrowers.

\subsection{Managerial implications}

If a C2C sharing platform utilizes dynamic twosided pricing and subsequently adjust its fees, it will either disadvantage borrowers over lenders (left side of Figure 3) or disadvantage lenders over borrowers (right side of Figure 3).

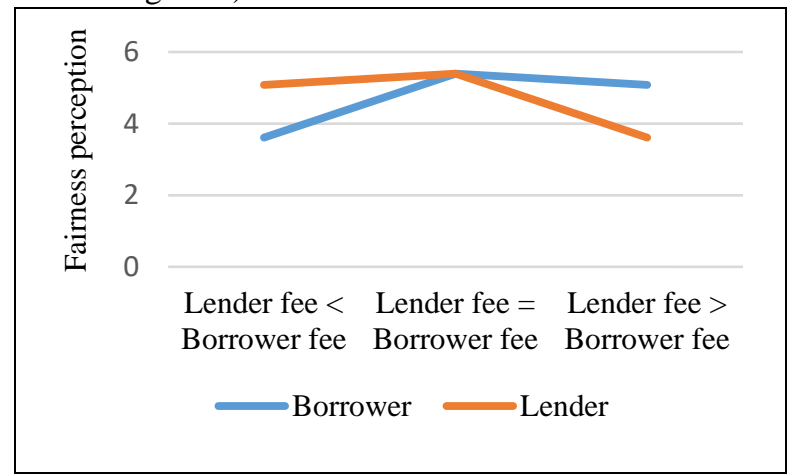

\section{Figure 3. Fairness perception of borrowers} and lenders

Expressed in numbers, fee differences between lenders and borrowers of $20 \%$ decrease mean fairness perception of the disadvantaged group by 1.783 and intention to share by approximately $25 \%$ compared to equal fees between both consumer groups. At the same time, fairness perception of the advantaged group decreases by only .315 and associated intention to share decreases by $2.8 \%$. This illustrates that fairness perception and intention to share of the disadvantaged group decreases below fairness perception and intention to share of the advantaged group. This leads to an imbalance of demand and supply even if a C2C sharing platform applies a dynamic two-sided platform pricing strategy and considers the economic effects described in Angerer et al. [3]. Subsequently, a C2C sharing platform has to be aware of the tradeoff between the positive economic effect and the negative fairness effect when utilizing a dynamic two-sided platform pricing strategy.

\subsection{Limitations and future research}

The participants of this study were students of two Austrian universities. This may not sufficiently represent the user group of Airbnb.com especially with respect to demographic diversity of the participants. It may be useful to conduct a similar study outside the scope of the university to reveal potential differences.

We find that fairness perception is able to predict approximately $31.3 \%$ of variance in intention to share. In future research it may be interesting to hypothesize and test other factors that may influence intention to share. This may lead to a more complete explanation of what factors, beside fairness perception, describe intention to share in the sharing economy. In addition, a comparative analysis of the different factors may reveal the magnitude to which each of the factors is improving the prediction of intention to share. Subsequently, the different factors can be ranked according to their explanatory power towards the variance of intention to share.

In this study, our hypotheses are tested in the context of a $\mathrm{C} 2 \mathrm{C}$ sharing platform. To analyze if our findings also hold for two-sided platform business models in general, we plan to test the hypothesis in different application contexts. However, we expect that we find similar results for other two-sided platforms.

\section{Conclusion}

From an economic perspective, dynamic pricing seems to be the profit maximizing pricing strategy for C2C sharing platforms because it allows for balancing supply and demand over time. However, the influence of dynamic pricing on consumer behavior remain unstudied. Based on distributed justice and equity theory we set up a laboratory experiment and investigate the effect of two characteristics of dynamic pricing, namely fee differences across consumer groups and fee changes over time, on fairness perception of consumers of a $\mathrm{C} 2 \mathrm{C}$ sharing platform and how fairness perception affects intention to share. We find that fee differences across consumer groups as well as fee changes over time have a negative effect on fairness perception and intention to share. Comparing the effect sizes, fee differences across consumer groups have a substantially stronger negative effect on fairness perception than fee changes over time. Especially the consumer group that is charged with a higher fee has a lower intention to share resulting from negative fairness perception. Consequently, $\mathrm{C} 2 \mathrm{C}$ sharing platforms have to be aware of the negative effects from fairness perception when they implement a dynamic two-sided pricing strategy. Overall, $\mathrm{C} 2 \mathrm{C}$ sharing platforms have to balance the 
positive economic effect described in [3] and the negative fairness effect on intention to share.

\section{References}

[1] Airbnb, "Terms of Service", https://www.airbnb.com/ terms , 2017.

[2] Adams, J. S., "Inequity In Social Exchange", Advances in Experimental Social Psychology, (2:1), 1965, pp. 267-299.

[3] Angerer, P., M. P. Müller, and S. Zimmermann, "Optimal Pricing Behavior of Online Sharing Platforms", Journal of the Association for Information Systems, forthcoming.

[4] Blattberg, C., R. Briesch, and E. Fox, "How Promotions Work", Marketing Science, (14:3), 1995, pp. 122-132.

[5] Campbell, M. C., "Perception of Price Unfairness: Antecedents and Consequences", Journal of Marketing Research, (36:2), 1999, pp. 187-199.

[6] Charness, G., U. Gneezy, and M. A. Kuhn, "Experimental methods: Between-subject and within-subject design", Journal of Economic Behavior and Organization, (81:1), 2012, pp. 18.

[7] Cox, J. L., "Can differential prices be fair?", Journal of Product \& Brand Management, (10:5), 2001, pp. 264-275.

[8] Dervojeda, K., D. Verzijil, F. Hagtagaal, M. Lengton, E. Rouwmaat, E. Monfardini, and L. Frideres, "The sharing Economy: Acessibility based business models for peer-topeer markets", European Commission: Businesss Innovation Observatory, 2013.

[9] Eisenmann, T., G. Parker, and M. W. Van Alstyne, "Strategies for two-sided markets", Harvard Business Review, (84:10), 2006, pp. 92-101.

[10] Elmaghraby, W., and P. Keskinocak, "Dynamic Pricing in the Presence of Inventory Considerations: Research Overview, Current Practices, and Future Directions", Management Science, (49:10), 2003, pp. 1287-1309.

[11] Field, A., Discovering Statistics using SPSS, SAGE Publications Ltd, London, 2009.

[12] Friedman, D., and S. Sunder, Experimental Methods: A Primer for Economists, Cambridge University Press, Cambridge, 1994.

[13] Garbarino, E., and S. Maxwell, "Consumer response to norm-breaking price events in e-commerce", Journal of Business Research, (63:9-10), 2010, pp. 1066-1072.

[14] Grewal, D., D. M. Hardesty, and G. R. Iyer, "The Effects of Buyer Identification and Purchase Timing on Consumers' Perceptions of Trust, Price Fairness, and Repurchase Intentions", Journal of Interactive Marketing, (18:3), 2004, pp. $87-100$

[15] Hair, F. J., W. C. Black, B. J. Babin, and R. E. Anderson, Multivariate Data Analysis: A Global Perspective, Pearson Education, New Jersey, 2010.

[16] Hausemer, P., J. Rzepecka, M. Dragulin, S. Vitiello, L. Rabuel, M. Nunu, A. R. Diaz, "Exploratory study of consumer issues in online peer-to-peer platform markets" European Commission, 2017.

[17] Haws, K. L., and W. O. Bearden, "Dynamic Pricing and Consumer Fairness Perceptions", Journal of Consumer Research, (33:3), 2006, pp. 304-311.
[18] Homans, G. C, Social Behaviour: Its Elementary Forms, Harcourt, Brace \& World Inc., New York, 1961.

[19] Kahneman, D., J. L. Knetsch, and R. H. Thaler, "Fairness and the Assumptions of Economics", The Journal of Business, (59:4), 1986, pp. 285-300.

[20] Kannan, P. K., and K. K. Praveen, "Dynamic Pricing on the Internet: Importance and Implications for Consumer Behavior", International Journal of Electronic Commerce, (5:3), 2001, pp. 63-83.

[21] King, C., and D. Narayandas, "Coca-Cola's New Vending Machine (A): Pricing to Capture Value, or Not?", Harvard Business School, 2000.

[22] Lee, S., A. Illia, and A. Lawson-Body, "Perceived price fairness of dynamic pricing", Industrial Management \& Data Systems, (111:4), 2011, pp. 531-550.

[23] Maxwell, S.,"Rule-based price fairness and its effects on willingness to purchase", Journal of Economic Psychology, (23:2), 2002, pp. 191-212.

[24] Moors, G., N. D. Kieruj, and J. K. Vermunt, "The Effect of Labeling and Numbering of Response Scales on the Likelihood of Response Bias", Sociological Methodology, (44:1), 2014, pp. 369-399.

[25] Mussweiler, T., E. Birte, and F. Strack, Anchoring effect, in Cognitive illusions. A handbook on fallacies and biases in thinking, judgement and memory, R. F. Pohl (eds.), Psychology Press, New York, 2004, pp. 183-200.

[26] Podsakoff, P. M., S. B. MacKenzie, J. Y. Lee, and N. P. Podsakoff, "Common method biases in behavioral research: A critical review of the literature and recommended remedies", Journal of Applied Psychology, (88:5), 2003, pp. 879-903.

[27] Reinartz, W., "Customizing Prices in Online Markets", Emerging Issues in Management, (1), 2002, pp. 55-65.

[28] Reynolds, N., and A. Diamantopoulos, "The effect of pretest methods on error detection rates: Experimental evidence", European Journal of Marketing, (32:5), 1998, pp. 480-498.

[29] Schmelzer, J., "United airlines moving to get friendlier with web commerce", http://articles.chicagotribune.com /2000-01-17/business/00 01170151_1_round-trip-domesticticket-united-airlines-reservation-systems, 2000.

[30] Schmider, E., M. Ziegler, E. Danay, L. Beyer, and M. Bühner, "Is It Really Robust?: Reinvestigating the Robustness of ANOVA Against Violation of the Normal Distribution Assumption", European Journal of Research Methods for the Behavioral and Social Sciences, (6:4), 2010, pp. 147-151.

[31] Thibaut, J., and L. Walker, Procedural justice: A psychological analysis, L. Erlbaum Associates, Hillsdale, 1975.

[32] Weiner, J, "Is Uber's surge pricing fair?", https://www.washingtonpost.com/blogs/she-the-people/wp/ 2014/12/22/is-ubers-surge-pricing-fair/?utm_term=.0c7ac423 3830, 2014.

[33] Xia, L., and K. B. Monroe, "Is a good deal always fair?: Examining the concepts of transaction value and price fairness", Journal of Economic Psychology, (31:6), 2010, pp. 884-894.

[34] Xia, L., K. B. Monroe, and J. L. Cox, "The Price Is Unfair!: A Conceptual Framework of Price Fairness Perceptions", Journal of Marketing, (68:4), 2004, pp. 1-15. 